\title{
Can handkerchiefs be suitable for mouth-to-mouth ventilation?
}

Soichiro Nomoto1), Ryo Sagisaka, EMT-P,PhD²)3) , Koshi Nakagawa EMT-P4), Hideharu Tanaka MD,PhD'44),

Tsutomu Komine $\mathrm{PhD}^{1 / 3)}$

1. Graduate School of Science and Engineering, Chuo University, Tokyo, Japan

2. Department of Integrated Science and Engineering for Sustainable Society, Chuo University, Tokyo, Japan

3. Research Institute of Disaster Management and Emergency Medical System, Kokusikan University, Japan

4. Graduate School of Emergency Medical System, Kokushikan University, Tokyo, Japan

○中兵大学

人国土舘大学

\section{OBJECTIVE}

This study analyzed whether handkerchiefs carried by many people can be ventilate as an alternative way to the Face Shield (FS).

\section{METHODS}

The inflow ventilation volume $(\mathrm{ml})$ was measured using a manikin(Resusci Anne) with three different fabric handkerchiefs (plain weave, twill weave, satin weave) and FS. Furthermore, plain weave was compared with FS in the number of four types of yarns $(210,240,250,260)$. Each of measurement was performed 10 times. The paramedics held the mask for ventilation using the EC technique of both hands. The differences in mean ventilation volume were analyzed by oneway analysis of variance and Tukey's multiple test. The level of significance for decision making was set at $\alpha=0.05$ (2-tailed).

\section{Ventilator}

(parapac200D)

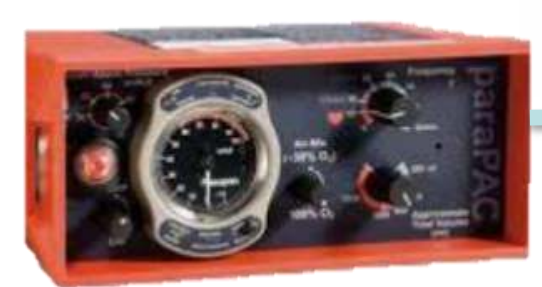

Pressure:20×100(pa) Tildalvolume:500(ml)

Resusci Anne

The paramedic held the mask.

Oxygen tube connected

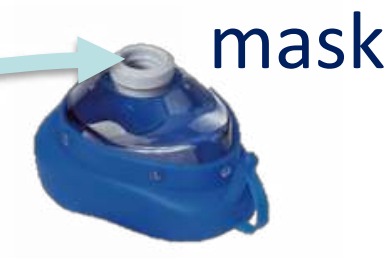

handkerchief
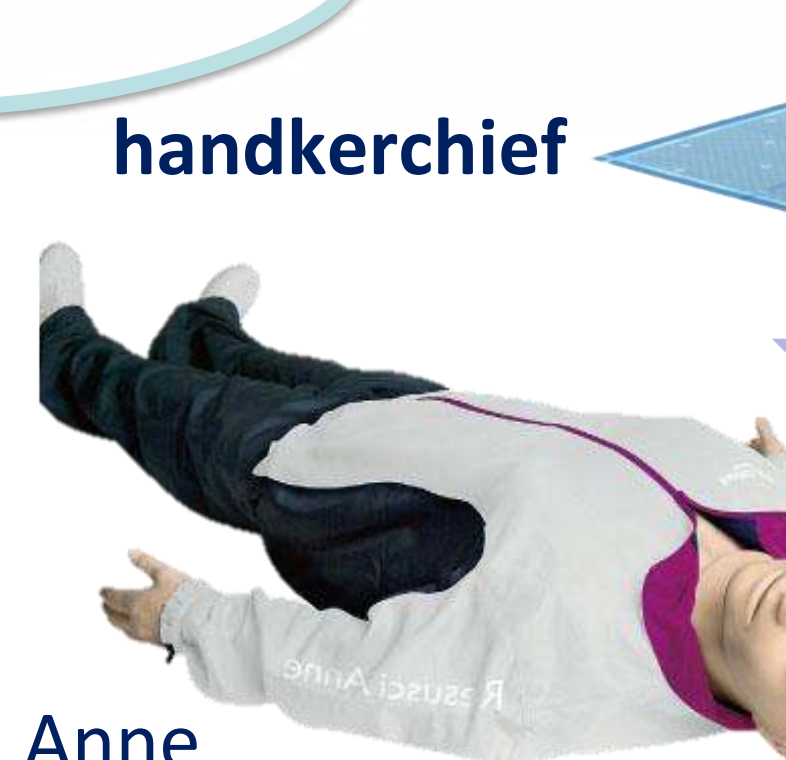

figure 1 :Experimental equipment and methods
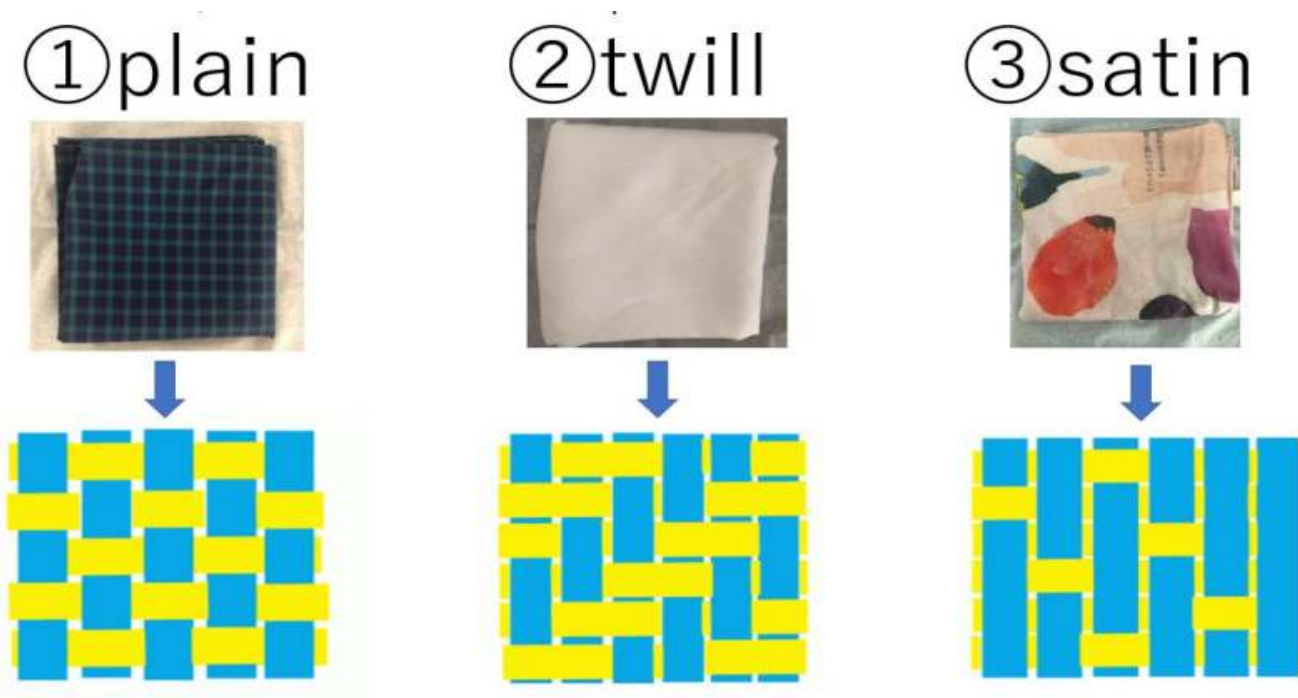

figure 2 :Type of handkerchief

\section{RESULTS}

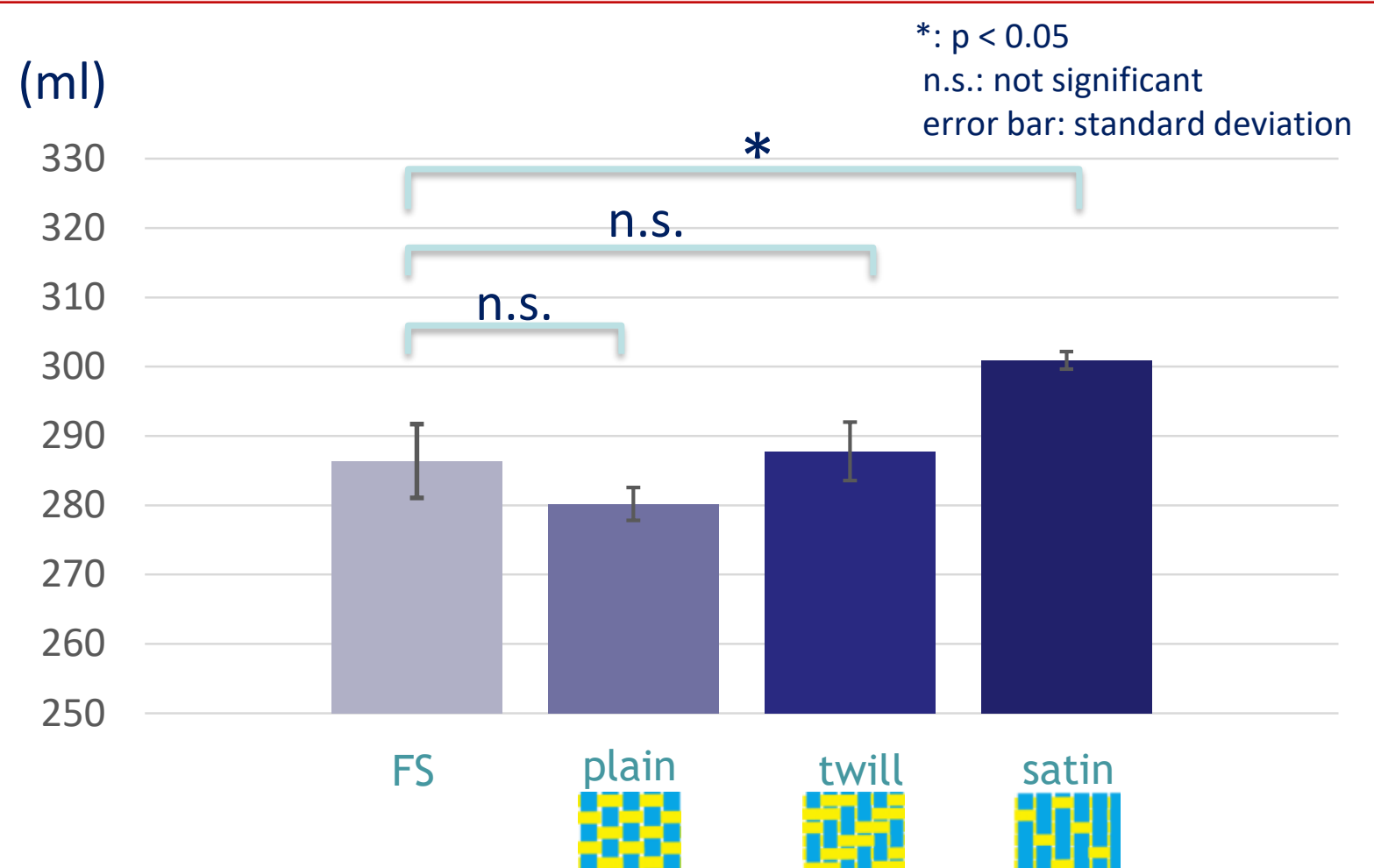

figure 3 :Relation of weave and average ventilation

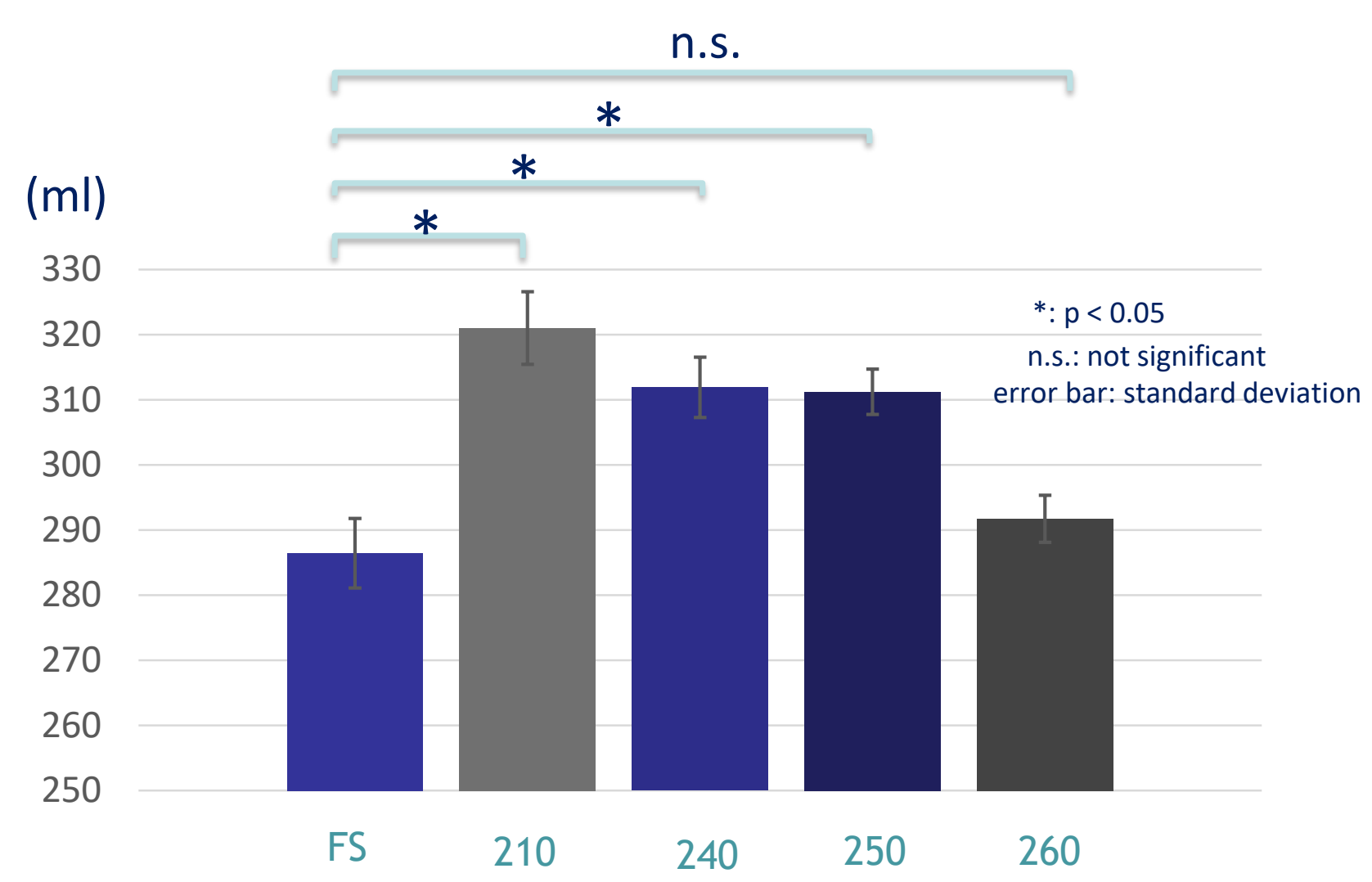

figure 4 :Relation of yarns and average ventilation

\section{DISCUSSION}

Satin, the dough is rough, is more ventilated than the other two. In terms of plain, as the density increases, the amount of oxygen supply decreases. But since the number of common handkerchief yarns on the market is 190 to 260 , at least the same amount of ventilation can be expected compared to the Face Shield.

\section{CONCLUSION}

In the case of not considering the infection, It was suggested that handkerchief could be used as an alternative to the Face Shield.

\section{CONTACT}

